\title{
Comminuted Displaced Fractures of Surgical Neck of Humerus Treated by PHILOS Plating
}

Dr. Lionel John ${ }^{1}$, Dr. Mohammed Irshad Basha $\mathrm{A}^{2^{*}}$, Dr. Vijayanarasimman Reddy ${ }^{3}$

${ }^{1}$ Associate Professor, Department of Orthopaedics, Sree Balaji Medical College and Hospital, Chromepet, Chennai, India

${ }^{2}$ Post Graduate, Department of Orthopaedics, Sree Balaji Medical College and Hospital, Chromepet, Chennai, India

${ }^{3}$ HOD and Professor, Department of Orthopaedics, Sree Balaji Medical College and Hospital, Chromepet, Chennai, India

DOI: $10.36347 /$ sjams.2020.v08i06.026

| Received: 18.12.2019 | Accepted: 25.12.2019| Published: 24.06.2020

*Corresponding author: Dr. Mohammed Irshad Basha A

Abstract

Original Research Article

In the aged population, fractures of the proximal part of humerus hold the place for highest incidence $(63 / 1000$ per year) next to the fractures of the distal radius and hip. Codman classified these fractures based on the mode of injury. Neer proposed a modification of this classification system. Their management remains conservative for the undisplaced ones and surgical treatment for the displaced type because they may lead to complications like malunion, non-union and a bad outcome. Our present study has been conducted prospectively on the patients admitted at our department at Sree Balaji Medical College and Hospital, Chennai with fracture of the surgical neck of humerus. These patients were managed by open reduction followed by internal fixation using proximal humerus locking plate (PHILOS plate). The outcome was assessed on the basis of Neer's scoring system. Results were quite promising in our patients thus indicating the proximal humerus locking plate to be a good treatment option.

Keywords: Surgical neck, humerus, PHILOS plate, fracture.

Copyright @ 2020: This is an open-access article distributed under the terms of the Creative Commons Attribution license which permits unrestricted use, distribution, and reproduction in any medium for non-commercial use (NonCommercial, or CC-BY-NC) provided the original author and source are credited.

\section{INTRODUCTION}

Fractures of the proximal humerus account for five to nine percent of all the fractures [1], being the second most common. Most of these type of fractures are stable and displaced only minimally, thereby validating conservative management [2]. This can be done by sling immobilisation and physiotherapy [3]. However, surgical management is necessary for displaced fractures which is quite challenging. Nonoperative treatment of these displaced proximal humerus fractures have been associated with a poor outcome like non-union, malunion and avascular necrosis [4]. Various surgical modalities are available with variable results. These include closed reduction and percutaneous fixation, transosseous suture fixation [5], open reduction and internal fixation using plates, locking plate fixation and hemiarthoplasty $[2,6]$. One of the advantages of closed reduction along with percutaneous fixation is it requires comparatively minimal dissection thereby lesser compromise over the vascular supply $[7,8]$. But this does not prove the same in osteoporotic bone. The other methods are also associated with noteworthy complications like nonunion, malunion, impingement and rotator cuff impairment [8].
The proximal humerus interlocking plate (PHILOS) plate provides a good treatment option for these fractures. The locking plate is a single beam construct thereby allowing no motion in between the components - the plate, screw and bone. Thus they serve four times stronger compared to the load sharing beam constructs. As these plates are precontoured for the proximal humerus, the need for a plate to bone compression using locking screws is bypassed, also with an advantage of preservation of blood supply to the bone. They also reduce the risk of malreduction [9].

The aim of our present study is to determine the functional outcome of the displaced fractures of surgical neck of humerus treated using locking plates by Neer's shoulder score.

\section{Materials And Methods}

One of the major advantages of PHILOS plate is gentle reduction of the fracture by indirect methods, even in cases with a poor bone quality. This is due to the combination of plate-screw locking at fixed angle with the screws placed three dimensionally over the head of humerus, thus requiring shorter immobilisation and permitting earlier exercise. 
A prospective study was conducted on patients admitted with displaced fractures of surgical neck of humerus of closed type in our department at Sree Balaji Medical College and Hospital, Chennai during the period from March 2017 to February 2018. This included a total of 15 patients - 9 males and 6 females. The patients with fractures of closed type - 2part, 3 part and 4 part fractures displacement more than $1 \mathrm{~cm}$ and a varus angulation of more than 45 degree were included in the study. Those with open fractures of severe comminuted type, fractures with minimal displacement and pathological fractures were excluded from the study. The mean age of the patients was 35 years.

The patients were evaluated clinically for tenderness, swelling, deformity and neuro vascular deficit. Hematological and radiological investigations were performed preoperatively and anaesthetic fitness obtained. Informed written consent was obtained from the patients.

\section{Operating Technique}

The patients were taken up for surgery in a beach chair position under general anesthesia along with a regional block. Patients were put on perioperative intravenous antibiotic coverage. Deltopectoral approach was employed by a 8 to $10 \mathrm{~cm}$ incision from the coracoid process. Dissection was done more lateral to the bicipural groove to avoid vascular damage. The nervous plane between the pectoralis major and deltoid muscle was identified carefully and separated and the cephalic vein was retracted. The subscapularis muscle was incised along its fibers after making it taut in external rotation. After clearing the fracture hematoma, the fracture fragments were identified and reduced. The reduction was checked in both the views.

The PHILOS plate (proximal humerus interlocking plate) was placed and fixed with screws. The tuberosity was fixed through the plate holes. Finally reduction was confirmed using $\mathrm{C}$-arm in both the views. The rotator cuff muscles were sutured and proper meticulous closure of the wound was performed. The arm was kept in a sling pouch postoperatively. Mobilisation exercises started from the first postoperative day under physiotherapist guidance. Suture removal was done by 12 th postoperative day.
The patients were followed up and assessed 2 weeks, 6 weeks, 3 months and if possible 6 months postoperatively. Radiological assessment was performed in AP and lateral scapular views in internal and external rotation to look for fracture union, in terms of cotical continuity. Complications like avascular necrosis and loss of fixation were also looked for. Clinically pain, range of motion and return of function were assessed.

\section{RESULTS}

A total of 15 patients with displaced fracture of surgical neck of humerus were treated by PHILOS plating in order to evaluate the radiological and functional results. Their average age was 35 years with a more of male preponderance (Male to female ratio $3: 2$ ). The mode of injury was by fall in 11 patients and by road traffic accident in four. The interval between the injury and surgery was around 2 to 3 days.

As per Neer's classification system for proximal humerus fractures, 9 patients had two-part fracture, 4 had three-part and 2 patients had four-part fracture. The average surgical duration was 95 mins. No intra operative or immediate postoperative complications were observed. One patient developed superficial surgical wound infection which subsided with debridement, antibiotics and regular aseptic dressing. Complications like screw backing, breaking of screw /plate was observed in none of our patients.

Fracture union was observed radiologically by 12 to 14 weeks. No limitation of physical activity was observed in the patients during followup except one, who had mild to moderate limitation during recreational activity.

Maximum abduction possible at followup was 160 degrees. Forward flexion was possible upto a maximum if 170 degrees. Full range external rotation was possible in most cases. None of the cases experienced complications like shoulder impingement or avascular necrosis.

As per Neer's scoring system (Table-1), 5 patients $(33.3 \%)$ had excellent results, 8 patients $(53.3 \%)$ had a satisfactory outcome and 2 patients $(13.3 \%)$ had unsatisfactory results. 


\section{Table-1: Neer's scoring system}

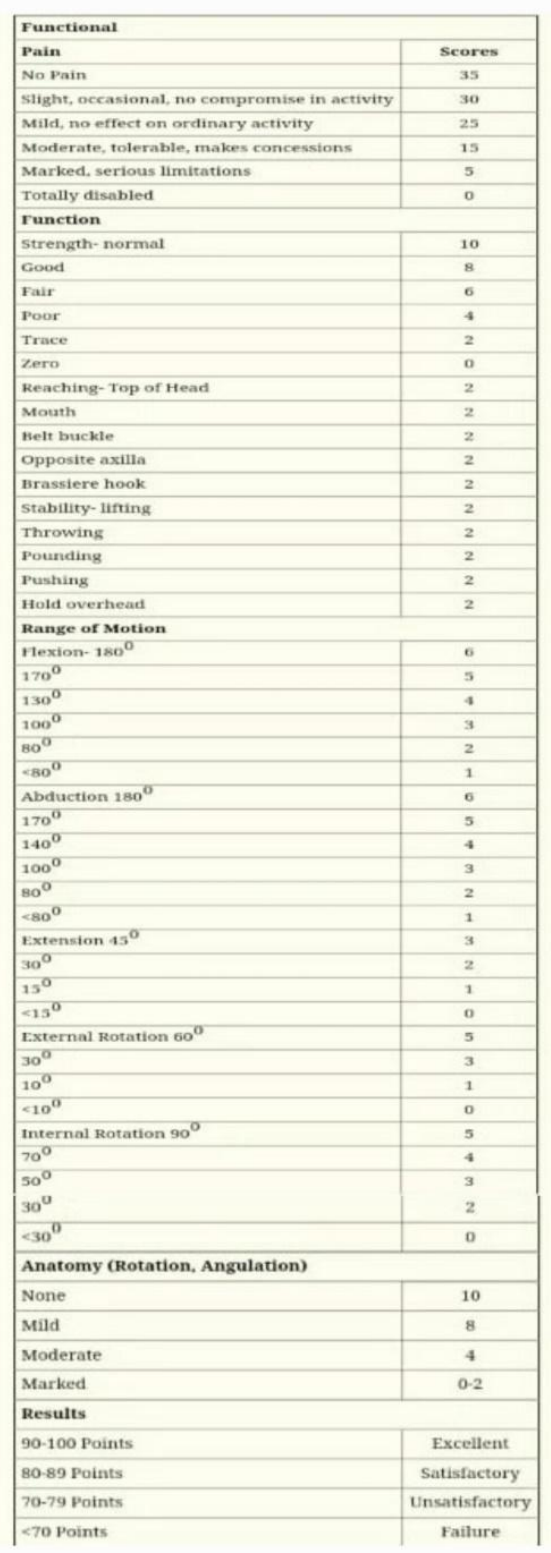

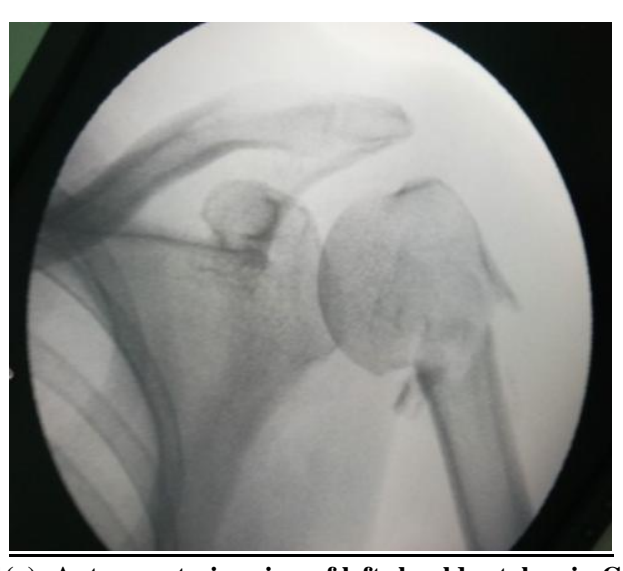

Fig-1(a): Anteroposterior view of left shoulder taken in C-arm showing displaced fracture of the surgical neck of humerus with varus angulation

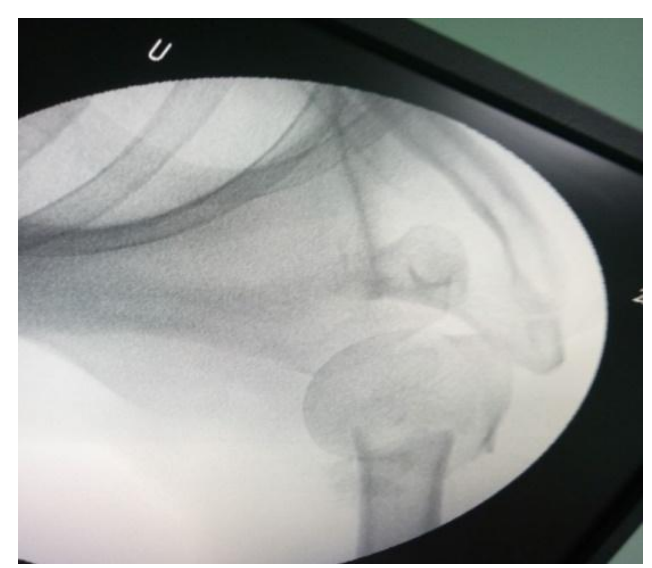

Fig-1(b): Axial view of the same patient taken on C-arm 


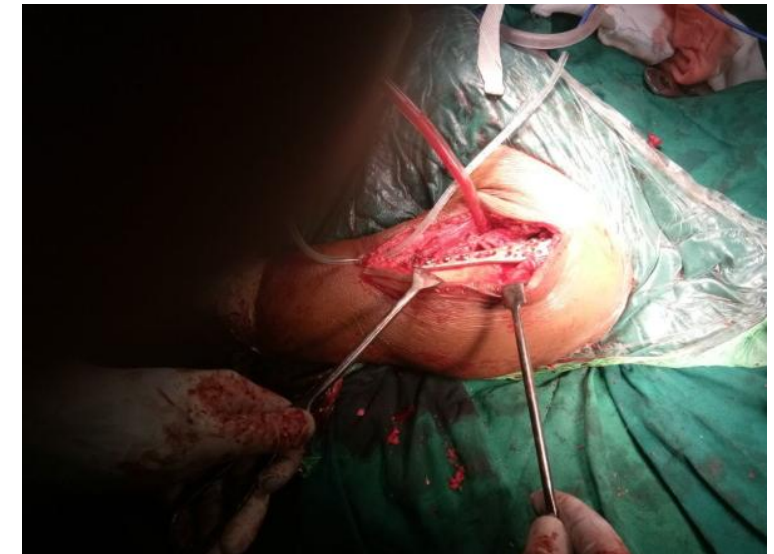

Fig-1(c): Intraoperative picture - Fracture reduced and PHILOS plating being done

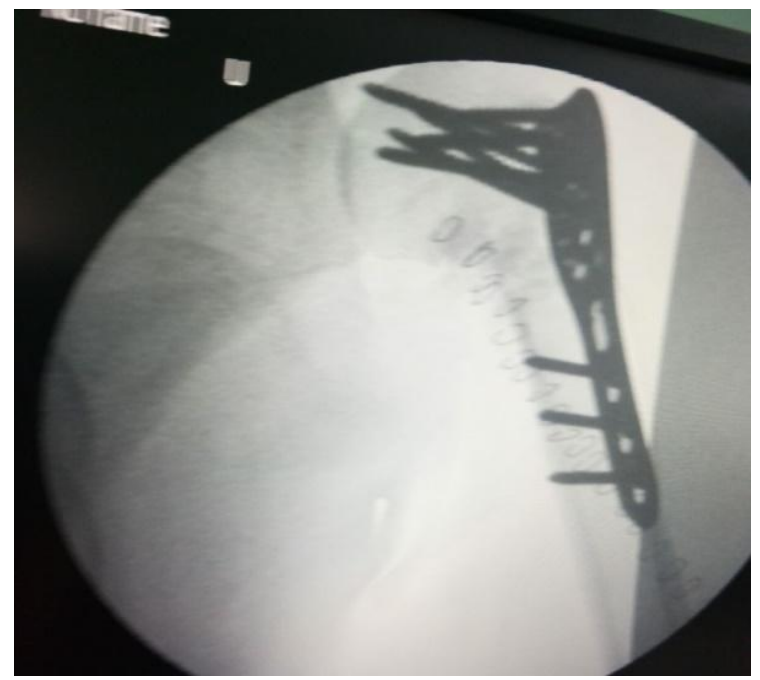

Fig-1(d): C-arm picture showing the reduced fracture fixed with the proximal humerus locking plate

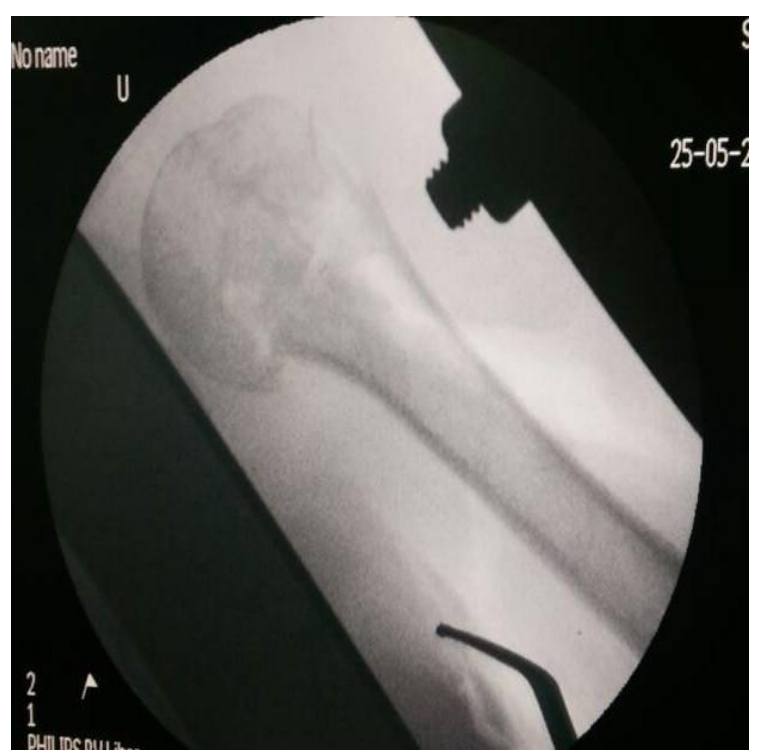

Fig-2(a): Anteroposterior view of the right humerus of a 76 year old female showing fracture along the surgical neck

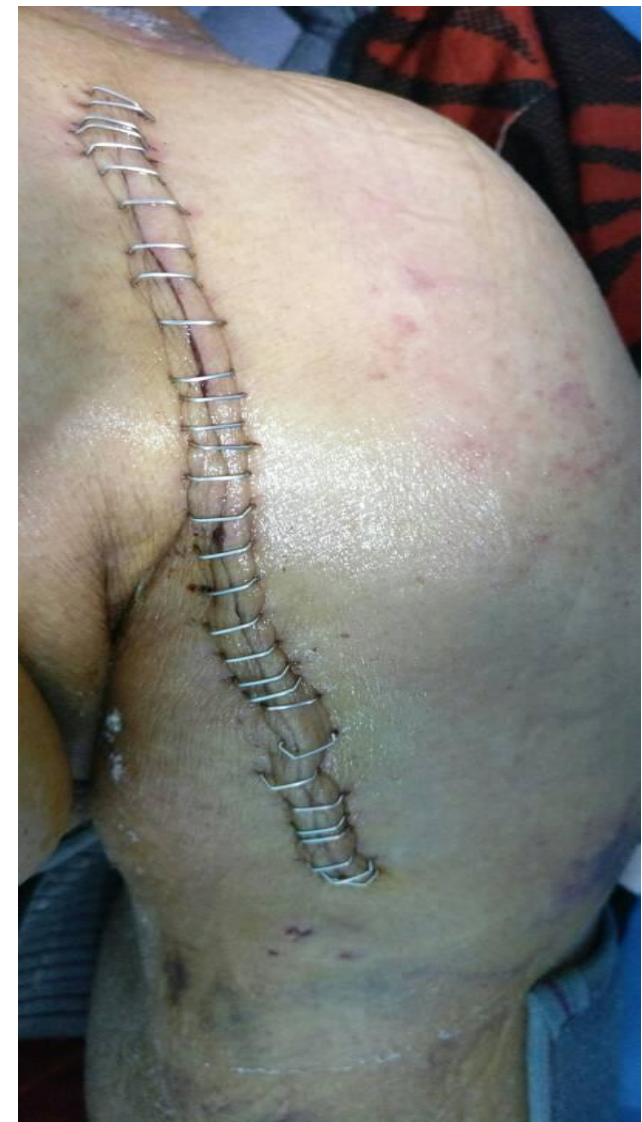

Fig-2(b): Postoperative picture of the patient after fracture reduction and PHILOS plate fixation and stapling of the operative wound

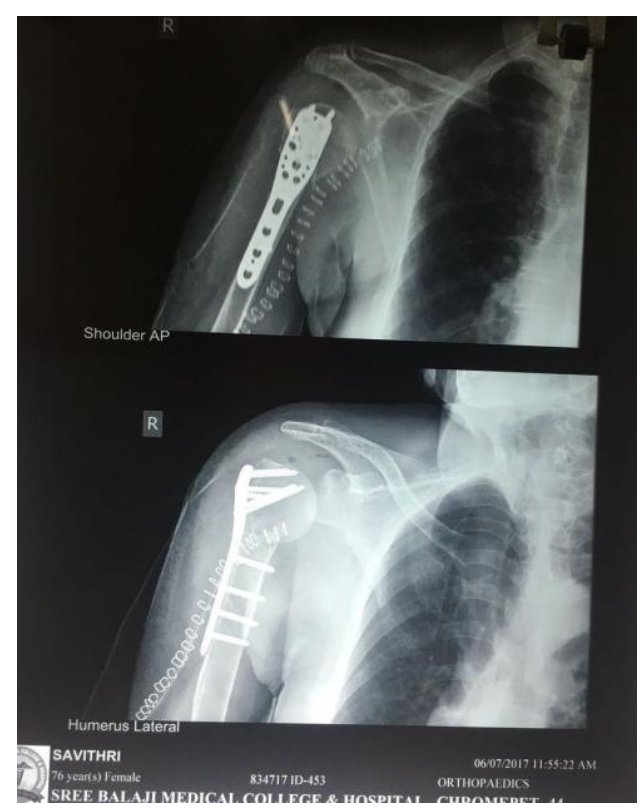

Fig-2(c): Postoperative Xray - AP and lateral views showing successful fracture reduction and fixation by PHILOS plate

\section{DISCUSSION}

Fractures of the proximal humerus are quite challenging to treat. The undisplaced variety can be satisfactorily managed conservatively. However, fractures with an intra-articular extension, displaced varieties and those with severe comminution demand 
surgical management $[2,11]$. The primary aim of this surgical treatment is restoration of function as to resume the day to day activities earlier. The various surgical options include percutaneous $\mathrm{K}$ - wiring, $\mathrm{T}$ plate [12, 13], blade plate [14], one third tubular plate [15], tension band wiring [16], helix wiring [17], external fixator [18, 19], intramedullary nail [20, 21], locking plate [8, 10, 22, 23] and hemiarthoplasty [24].

Each method has its own advantages and disadvantages. Percutaneous pinning while associated with lesser soft tissue injury and neuro vascular complications, it does not ensure adequate reduction of the fracture thereby delaying mobilisation and healing. It is also associated with complications like infection along the tract of the pin [25]. The results of tension band wiring were quite similar to those treated nonoperatively $[4,26]$. T-plates have shown poor results in patients with osteoporosis along with complications like avascular necrosis, loosening of screw [27, 28]. On the other hand, locking plates have proved to show a better functional outcome in these cases $[14,29,30]$. They have become the standard treatment of choice for fractures of the proximal humerus, especially of displaced type [31, 32]. In these locking plates, the force is transmitted to the blade of the plate through the locking screws from the bone. This helps in providing more stability and lesser complication rate [33].

In our present study, the common mode of injury was fall with a significant male preponderance. The common fracture pattern associated was 2 part fracture. The mean duration between injury and surgery was 2.5 days.

None of the patients in our study had associated neuro vascular damage. The average time to union observed radiologically was 12 to 14 weeks. The results were excellent in $33.3 \%$, good in $53.3 \%$ and bad in $13.3 \%$ of the patients. Problems like loss of reduction, displacement of fragments were not seen in out patients. The proximal humerus locking plate provides an excellent treatment option for fratures of the surgical neck of humerus, even in patients with osteoporosis. Fragment collapse is prevented by the angular stability, proper and sufficient buttressing and support of load sharing. Thus it can be used in 2 part, 3 part and 4 part fractures, both in the young and the aged population, provided proper surgical technique is used.

\section{CONCLUSION}

Our current study shows that the proximal humerus locking plate is an assuring treatment option for fractures of the surgical neck of humerus, including osteoporotic bones. The implant provides support inferomedially through the locking screws and buttressing effect laterally. In the whole, the PHILOS plate is better in terms of functional and radiological outcome in displaced fractures of surgical neck of humerus. The major limitations of our study is a smaller sample and shorter period of followup with lesser osteoporotic patients. However, the treatment was much fruitful in the adult patients of our study group.

\section{REFERENCES}

1. Badman BL, Mighell M. Fixed-angle locked plating of two-, three-, and four-part proximal humerus fractures. J Am Acad Orthop Surg. 2008;16:294-302.

2. Nho SJ, Brophy RH, Barker JU, Cornell CN, MacGillivray JD. Management of proximal humeral fractures based on current literature. J Bone Joint Surg Am. 2007;89:44-58.

3. Iannotti JP, Ramsey ML, Williams GR, Warner JJP. Nonprosthetic management of proximal humeral fractures. J Bone Joint Surg Am. 2003;85:1578-93.

4. Zyto K. Non-operative treatment of comminuted fracture of proximal humerus in elderly patients. Injury. 1998;29(5):349-52.

5. Chen CY, Chao EK, Tu YK, Ueng SW and Shih $\mathrm{CH}$. Closed management and percutaneous fixation of unstable proximal humerus fractures. Journal Trauma 1998;45(6):1039-45.

6. Michael W, Andre F, Robert F. Locked plating: biomechanics and biology and locked plating: clinical indications. Techniques in Orthopaedics. 2007;22(4):209-218.

7. Codman EA. Fractures in relation to the subacromial bursa. In: Codman EA (editor), The Shoulder: Rupture of the Supraspinatus Tendon and Other Lesions in or About the Subacromial Bursa. Boston MA: Thomas Todd 1934;313-33.

8. Kilic B, Uysal M, Cinar BM, Ozkoc G, Demirors $\mathrm{H}$ and Akpinar S. Early results of treatment of proximal humerus fractures with the PHILOS locking plate. Acta Orthop Traumatol Turc, 2008;42(3):149-53.

9. Robinson CM, Page RS, Hill RM, Sanders DL, Court-Brown CM, Wakefield AE. Primary hemiarthroplasty for treatment of proximal humeral fractures. Journal Bone Joint Surg Am. 2003;85:1215-23.

10. Moonot P, Ashwood N, Hamlet M. Early results for treatment of three-and four-part fractures of the proximal humerus using the PHILOS plate system. The Journal of bone and joint surgery. British volume. 2007 Sep;89(9):1206-1209.

11. Friess DM, Attia A, Vallier HA. Locking plate fixation for proximal humerus fractures: a comparison with other fixation techniques. Orthopedics. 2008 Dec 1;31(12).

12. Resch H, Povacz P, Frohlich R and Wambacher M. Percutaneous fixation of three and four-part fractures of the proximal humerus. Journal Bone Joint Surg, 1997;79(2):295-300.

13. Soete PJ, Clayson PE and Costenoble VH. Transitory percutaneous pinning in fractures of the proximal humerus. Journal Shoulder Elbow 
Surgery, 1999; 8(6):569-73.

14. Siffri PC. Biomechanical analysis of blade plate versus locking plate fiaxtion for a proximal humerus fracture: comparison using cadaveric and synthetic humer. Journal Orthop Trauma 2006;20:547-54.

15. Wanner GA, Wanner-Schmid E, Romero J, Hersche O, von Smekal A, Trentz O, Ertel W. Internal fixation of displaced proximal humeral fractures with two one-third tubular plates. Journal Trauma. 2003;54(3):536-44.

16. Lu CC, Chang MW and Lin GT. Intramedullary pinning with tension-band wiring for surgical neck fractures of the proximal humerus in elderly patients. Kaohsiung Journal Medical Science, 204;20(11):538-45.

17. Rassaidat K, Struben PJ, van Loon CJ. Helix wire osteosynthesis for proximal humeral frctures: unacceptable non-union rate in two and three-part fractures. Arch Orthop Trauma Surg. 2004;124(3):166-8.

18. Monga P, Verma R, Sharma VK. Closed reduction and external fixation for displaced proximal humeral fractures. Journal Orthop Surg. 2009; 17(2):142-145.

19. Nabil AE, Vishwas $P$ and Adeel H. Mini-external fixation of two and three-part proximal humerus fractures. Acta Orthop Belg. 2007;73:437-42.

20. Kumar V, Datir S, Venkateswaran B. Intramedullary nailing for displaced proximal humeral fractures. Journal Orthop Surg. 2010;18(3):324-7.

21. Lin J, Hou SM, Hang YS. Locked nailing for displaced surgical neck fractures of the humerus. Journal Trauma. 1998;45(6):105.

22. Gradl G, Dietze A, Kääb M, Hopfenmüller W, Mittlmeier T. Is locking nailing of humeral head fractures superior to locking plate fixation?. Clinical Orthopaedics and Related Research®. 2009 Nov 1;467(11):2986-2993.

23. Fazal MA, Haddad FS. Philos plate fixation for displaced proximal humeral fractures. Journal of Orthopaedic Surgery. 2009 Apr;17(1):15-8.

24. Kralinger F, Schwaiger R, Wambacher M, Farrell E, Menth-Chiari W, Lajtai G, Hübner C, Resch H. Outcome after primary hemiarthroplasty for fracture of the head of the humerus: a retrospective multicentre study of 167 patients. The Journal of bone and joint surgery. British volume. 2004 Mar;86(2):217-9.

25. Jaura GS, Sikdar J, Singh S. Long term results of PHILOS plating and percutaneous $\mathrm{K}$ wire fixation in proximal Humerus fracture in the elderly. Malaysian Orthopaedic Journal. 2014;8(1):4-7.

26. Ilchmann T, Ochsner PE, Wingstrand H, Jonsson $\mathrm{K}$. Non-operative treatment versus tension-band osteosynthesis in three- and four-part proximal humeral fractures. A retrospective study of 34 fractures from two different trauma centers. Int Orthop. 1998;22(5):316-20.

27. Rees J, Hicks J, Ribbans W. Assessment and management of three-and four-part proximal humeral fractures. Clin Orthop Relat Res. 1998;353:18-29.

28. Kristiansen B, Christensen SW. Plate fixation of proximal humeral fractures. Acta Orthop Scand. 1986;57(4):320-23.

29. Weinstein DM, Bratton DR, Ciccone WJ II, Elias JJ. Locking plates improve torsional resistance in the stabilization of three-part proximal humeral fractures. Journal Shoulder Elbow Surg. 2006;15(2):239-43.

30. Walsh S, Reindl R, Harvey E, Berry G, Beckman L, Steffen T. Biomechanical comparison of a unique locking plate versus a standard plate for internal fixation of proximal humerus fractures in a cadaveric model. Clin Biomech. 2006;21(10):1027-31.

31. Fankhauser F, Boldin C, Schippinger G, Haunschmid C, Szyszkowitz R. A new locking plate for unstable fractures of the proximalhumerus. Clin Orthop Relat Res. 2005;430:176-81.

32. Gallo RA, Zeiders GJ, Altman GT. Two-incision technique for treatment of complex proximal humerus fractures. Journal Orthop Trauma. 2005;19:734-40.

33. Lill H, Hepp P, Korner J, Kassi JP, Verheyden AP, Josten C, Duda GN. Proximal humeral fractures: how stiff should an implant be?. Archives of orthopaedic and trauma surgery. $2003 \mathrm{Apr}$ $1 ; 123(2-3): 74-81$. 